\title{
Readers detect an low-level phonological violation between two parafoveal words 许, 败访
}

\author{
Michael G. Cutter ${ }^{\mathrm{a}, \mathrm{b}, *}$, Andrea E. Martin ${ }^{\mathrm{c}, \mathrm{d}}$, Patrick Sturt ${ }^{\mathrm{a}}$ \\ ${ }^{a}$ The University of Edinburgh, United Kingdom of Great Britain and Northern Ireland \\ ${ }^{\mathrm{b}}$ The University of Nottingham, United Kingdom of Great Britain and Northern Ireland \\ ${ }^{\mathrm{c}}$ Max Planck Institute for Psycholinguistics, the Netherlands \\ ${ }^{\mathrm{d}}$ Donders Centre for Cognitive Neuroimaging, Radboud University, the Netherlands
}

\section{A R T I C L E I N F O}

\section{Keywords:}

Parafoveal processing

$n+2$ preview benefit

Phonological processing

Contextual fit effects

Reading

\begin{abstract}
A B S T R A C T
In two eye-tracking studies we investigated whether readers can detect a violation of the phonological-grammatical convention for the indefinite article an to be followed by a word beginning with a vowel when these two words appear in the parafovea. Across two experiments participants read sentences in which the word an was followed by a parafoveal preview that was either correct (e.g. Icelandic), incorrect and represented a phonological violation (e.g. Mongolian), or incorrect without representing a phonological violation (e.g. Ethiopian), with this parafoveal preview changing to the target word as participants made a saccade into the space preceding an. Our data suggests that participants detected the phonological violation while the target word was still two words to the right of fixation, with participants making more regressions from the previewed word and having longer go-past times on this word when they received a violation preview as opposed to a non-violation preview. We argue that participants were attempting to perform aspects of sentence integration on the basis of low-level orthographic information from the previewed word.
\end{abstract}

\section{Introduction}

It has long been known that when processing written language, readers do not just make use of visual information from the currently fixated word (e.g., see McConkie \& Rayner, 1975; Rayner, 1975). Rather, they also process at least one upcoming word parafoveally, prior to direct fixation. In recent years there has been an increased focus on both whether a word's contextual fit becomes apparent on the basis of parafoveal processing (e.g. Angele \& Rayner, 2013; Brothers \& Traxler, 2016; Schotter \& Jia, 2016; Veldre \& Andrews, 2016, 2018a; Wakeford \& Murray, 2013) and whether readers extract information from a word further into the parafovea during reading (i.e. from word $n+2$; see Angele \& Rayner, 2011; Angele et al., 2008; Cutter et al., 2014; Cutter et al., 2017; Kliegl et al., 2007; Radach et al., 2013; Rayner et al., 2007; Risse \& Kliegl, 2012). In the current paper we examine these two issues simultaneously, by examining whether participants' eye movement behaviour is influenced by a low-level phono-grammatical violation between word $n+1$ and word $n+2$ in the parafovea, such that word $n+1$ was always the indefinite article in the form an, while word $n+2$ was sometimes manipulated to begin with a consonant (e.g. Spanish).

\subsection{Parafoveal processing of word $n+1$}

A vast body of research has made use of the boundary paradigm (Rayner, 1975) to investigate the extent to which people parafoveally process the word directly after fixation (i.e. word $n+1$ ). In the boundary paradigm readers are given a preview of an upcoming word prior to direct fixation which is either correct, or incorrect with a varying level of overlap to the target word. As a reader's eyes cross an invisible boundary (typically located at the start of the space before the previewed word) the preview changes into the actual target word. By

\footnotetext{
${ }^{4}$ Michael G. Cutter, Department of Psychology, University of Edinburgh, Edinburgh, Scotland \& School of Psychology, University of Nottingham, Nottingham,

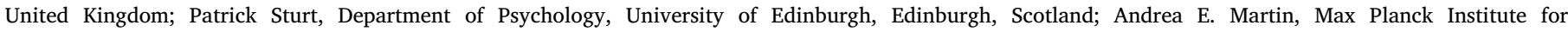
Psycholinguistics, Nijmegen, The Netherlands \& Donders Centre for Cognitive Neuroimaging, Radboud University, Nijmegen, The Netherlands.

Data files and R Scripts used in the analysis of our paper are available at https://osf.io/5sq8g/.

* Corresponding author at: School of Psychology, University of Nottingham, University Park Campus, Nottingham, NG7 2RD, United Kingdom of Great Britain and Northern Ireland.

E-mail address: michael.cutter@nottingham.ac.uk (M.G. Cutter).
} 
examining whether fixations on the target word are shorter following correct rather than incorrect previews it is possible to determine whether readers have partially processed this word parafoveally. A substantial number of studies have shown this is the case (see Cutter et al., 2015 for a review and Vasilev \& Angele, 2017, for a Bayesian metaanalysis). More interestingly, it is possible to determine what types of information readers extract from parafoveal words by comparing reading times on the word dependent upon whether the preview shares certain characteristics with the target word; for example, do readers fixate the target word for less time given a preview sharing phonology with the target word (e.g. beech as a preview for beach) than a preview that does not share this information (e.g. bench)?

In recent years, starting with Schotter (2013), our understanding of parafoveal processing has been greatly altered. Until recently it was generally assumed that readers only extracted relatively low-level information from a parafoveal word, such as orthographic (e.g. Briihl \& Inhoff, 1995; Hyönä et al., 2004; Johnson et al., 2007) and phonological codes (e.g. Ashby \& Rayner, 2004; Pollatsek et al., 1992). ${ }^{1}$ One way these effects were typically interpreted was in the framework of a trans-saccadic activation account, ${ }^{2}$ whereby readers would activate a candidate set of words on the basis of those words sharing abstract characteristics with the parafoveal preview (e.g., see Cutter et al., 2015). As such, target words would typically be easier to identify when preceded by a related preview than an unrelated preview.

However, recent work examining whether participants process semantic information from a parafoveal word (e.g. Hohenstein \& Kliegl, 2014; Rayner \& Schotter, 2014; Schotter, 2013), and, furthermore, whether readers are sensitive to a previewed word's fit into the preceding sentence context (Schotter \& Jia, 2016; Veldre \& Andrews, 2016; Veldre \& Andrews, 2018a; Wakeford \& Murray, 2013; Yang et al., 2014) has necessitated a reconsideration of the mechanisms underlying preview effects. In studies assessing whether participants are sensitive to a word's fit in the sentence, readers have been given previews of an upcoming word which was either plausible within the sentence context (e.g. modest as a preview for psycho in Melanie thought the man was really psycho...) or implausible within the sentence context (e.g. circus). These studies have typically found longer fixation durations on the target word given an implausible preview than a plausible preview. Furthermore, Veldre and Andrews (2018a) found that these effects were graded with the level of the unacceptability of the preview in the sentence context, such that fixations would be longer on the target word given a preview that violated both semantic and syntactic constraints of the sentence context (e.g. begin as a preview of stool in She eventually found a spare stool...) as opposed to a preview which violated just semantic constraints (e.g. uncle) or just syntactic constraints (e.g. landed as a preview of refuel in Her plane will probably refuel...). These findings are problematic for a trans-saccadic activation account of preview effects, since readers are gaining a preview benefit from a preview that should not be activating the target word to a greater extent than another preview.

As well as finding evidence for preview effects driven by the syntactic acceptability and plausibility of the previewed word in the sentence, recent studies have also observed such effects upon the probability of readers skipping a word. In their study, Veldre and Andrews (2018a) found that participants were less likely to skip a word which

\footnotetext{
${ }^{1}$ It should be noted that there is currently a controversy emerging over whether phonological preview effects are as large as previously assumed (Vasilev et al., 2019). For now we proceed under the assumption that these effects are real, although will return to this issue later due to its relevance to our own manipulation.

${ }^{2}$ This account has actually more typically been referred to as trans-saccadic integration, rather than activation. However, in the current paper we adopt the term activation so as to avoid confusion with the idea of people integrating an identified word into the sentence representation, another issue discussed in the current manuscript.
}

was either implausible or a poor syntactic fit in their sentences than words that fit into the sentence well. Trends in this direction were also present in earlier work by Veldre and Andrews (2016) and Schotter and Jia (2016). Furthermore, Brothers and Traxler (2016) found that a word of the incorrect syntactic class is less likely to be skipped than a word of an appropriate syntactic class. Finally, Cutter et al. (2020a) recently found evidence suggesting that predictability may exert less of an effect on the skipping of words in syntactically illegal positions than legal positions. It should be noted that these effects of contextual acceptability upon word skipping are not strong enough to override the influence of all other factors, such that readers will still skip a high-frequency syntactically illegal word more than a low-frequency syntactically illegal word (Angele et al., 2014; Veldre et al., 2020).

It should be clear from the above discussion that there is an increasing level of evidence that readers are sensitive to the contextual fit of a parafoveal word within the sentence context, both in terms of preview effects and word skipping. We will defer discussing theoretical explanations of these effects until further below. In our own study we investigate whether similar (but distinct) effects are observed for word $n+2$ in the parafovea. As such, it is necessary to briefly survey the existing literature of these effects.

\subsection{Word $n+2$ preview effects}

A great deal of recent research has focussed upon the extent to which word $n+2$ is processed prior to direct fixation and the factors affecting the extraction of information from word $n+2$ (e.g. Angele et al., 2008; Angele \& Rayner, 2011; Cutter et al., 2014; Cutter et al., 2017; Kliegl et al., 2007; Radach et al., 2013; Rayner et al., 2007; Risse \& Kliegl, 2012). Studies of this issue initially presented an unclear pattern of results, with some studies finding reliable $n+2$ preview effects, and others failing to find these effects. A recent Bayesian metaanalysis by Vasilev and Angele (2017) clarified the extent to which word $n+2$ is processed parafoveally. There are several findings from this Bayesian meta-analysis worth focusing on. First, it was found that the average size of the $n+2$ preview effect for studies using an alphabetic language was $3.9 \mathrm{~ms}$ in first fixation duration and $1.8 \mathrm{~ms}$ in gaze duration on word $n+2$ itself, with effects of $6.7 \mathrm{~ms}$ and $7.4 \mathrm{~ms}$ on word $n+1$. The effect on fixations on $n+2$ was $2.3 \mathrm{~ms}$ and $6.9 \mathrm{~ms}$ when analyses were restricted to studies using a three-letter word $n+1$, as opposed to longer words. Thus, the average effect size across studies is fairly small, suggesting that parafoveal processing of word $n+2$ is fairly minimal. As well as presenting average effect sizes, Vasilev and Angele presented 95\% credible intervals on the effect size across all studies, and across each individual study they examined. From these credible intervals, they also calculated the probability that the $n+2$ preview effect was greater than a certain magnitude. It is noteworthy that neither the credible interval for all studies combined nor for any individual study excluded an effect size of $0 \mathrm{~ms}$. Furthermore, the probability that the effect size in each measure was greater than $1 \mathrm{~ms}$ was only 0.70 and 0.53 for first fixation duration and gaze duration.

It should be clear from Vasilev and Angele's (2017) meta-analysis that $n+2$ preview effects are fairly modest in size, if they exist at all. It is also worth noting that these $n+2$ preview effects have generally been assessed by comparing conditions in which participants received a valid preview of word $n+2$ with conditions in which they received a preview consisting of a random letter string. In their meta-analysis Vasilev and Angele also examined the size of $n+1$ preview effects as a function of the type of parafoveal mask used, finding that for word $n+1$ these random letter masks tended to result in longer fixations on the target word than almost any other preview type (e.g. unrelated words; semantically, phonologically, or orthographically related words). As such, $n+2$ effects are generally very small despite researchers almost exclusively using false previews that should result in greater disruption than any other type of preview. Furthermore, it could 
well be the case that such small $n+2$ preview effects in prior studies could arise from methodological issues as opposed to genuine lexical processing of the parafoveal word. For example, Angele et al. (2016) demonstrated that readers are more likely to consciously detect that a word has changed during a saccade when the preview was non-wordlike rather than word-like, and, furthermore, that this detection of the change resulted in greater preview effects. As such, even the effects reported in Vasilev and Angele's meta-analysis may exaggerate the extent to which $n+2$ is processed parafoveally. It could be argued that this makes it highly unlikely that participants should process word $n+2$ to an extent where its fit in the sentence is assessed, and that any effect of our manipulation would be highly surprising.

Two prior studies have examined the effect of the contextual fit of word $n+2$ upon preview effects, albeit in a different way to our own study, and the studies discussed above examining word $n+1$ preview effects. The first of these studies was conducted by Radach et al. (2013), who presented subjects with sentences (e.g. Ashley quickly vacuumed the...) that either included a highly predictable target word (e.g. carpet) or an unpredictable target word (e.g. stairs). They used the boundary paradigm to manipulate the preview of this word until readers made a saccade beyond vacuum, with this preview either being a non-word (e.g. cwoyok) or the word of the opposite predictability (e.g. carpet as a preview of stairs), finding that reading times were longer on word $n+2$ when a highly predictable target was previewed with an unpredictable word or non-word mask, while reading times on an unpredictable target were longer when replaced with a highly predictable preview but not a non-word mask. These findings suggest that readers process word $n+2$ to a greater extent when they have a strong expectation of this word's identity, with subversions of these expectations leading to processing difficulty. Similarly, Cutter et al. (2014) found a larger than typical $n+2$ preview effect when word $n+2$ was the second constituent of a lexicalised spaced compound (e.g. bear in teddy bear) and was replaced with a non-word (e.g. hocu), and thus readers had a very strong expectation for the identity of this word. Together these studies suggest greater $n+2$ preview effects are observed when the preview of $n+2$ does not meet the expectations from the prior sentence context or word; however, these expectations have generally been for one specific word in prior studies, as opposed to just any word which meets one particular constraint.

\subsection{The current study}

In summary, readers process the first word to the right of fixation (i.e. word $n+1$ ) substantially while it is still in the parafovea, to the extent that it is possible for readers to assess that word's fit into the sentential context. Furthermore, these effects of sentential fit are not based upon any particular word being predictable, but rather on the extent to which a parafoveal word is consistent with a number of different constraints (i.e. syntactic and semantic). In contrast, readers seem to process very little information from word $n+2$, with existing studies suggesting that for the most part readers only extract low-level graphemic information from a word further into parafoveal vision. However, the effect of denying an accurate preview of word $n+2$ does seem to be larger in cases when the target word is particularly predictable (e.g. Cutter et al., 2014; Radach et al., 2013).

In the current study we examine whether readers process word $n+2$ in the parafovea to the extent that its compatibility with word $n+1$ is assessed at a phonological level. In our study participants read sentences in which the indefinite article an was followed by a proper noun (e.g. He thought losing against an Icelandic team was very embarrassing). We used the boundary paradigm to manipulate the preview of the proper noun until readers made a saccade beyond an, such that the parafoveal preview was visible as word $n+2$. In Experiment 1 we merely manipulated the preview to be correct (i.e. Icelandic) or incorrect and a violation of English phonological conventions, due to starting with a consonant (e.g. Mongolian). In Experiment 2 we included a third preview condition, in which the preview was incorrect but did not represent a violation of English phonological conventions (e.g. Ethiopian). ${ }^{3}$

To the best of our knowledge, only one prior study has examined eye movement behaviour in relation to this phono-grammatical rule (Slattery et al., 2006). In Slattery et al.'s study acronyms were used in which phonology was consistent with orthography (e.g. CIA is pronounced with an initial consonant; IRS is pronounced with a vowel) or inconsistent with orthography (e.g. FBI is pronounced with an initial vowel; USA is pronounced with an initial consonant). These acronyms followed either an or $a$, with the form of the article causing either a phonological violation (e.g. an USA, a FBI), an orthographic violation (e.g. an FBI, a USA), an orthographic and phonological violation (e.g. an CIA, a IRS) or no violation (e.g. an IRS, a CIA) between the two words. The effects of a phonological violation appeared in early fixation measures on the acronym (e.g. first fixation and gaze duration) while effects of an orthographic violation only appeared in later measures (e.g. go-past time, total time).Slattery et al. took this as evidence that readers rapidly detected a mismatch between the phonology of the acronym and preceding article. It should be noted that these findings may be specific to acronyms, due to the ambiguity between orthography and phonology. Indeed, Slattery et al. proposed that their finding may have been due to readers using the article to determine how to pronounce the acronym, leading to a cost when this cue was incorrect. Thus, while readers did indeed detect a violation early in this study, it is unclear whether the processes that resulted in this effect could be considered typical of the reading system, or if they only occur in acronyms in which there is a large level of ambiguity regarding pronunciation. Furthermore, the violations in this study were presented foveally, and so it is impossible to determine whether they were detected much earlier, in the parafovea, or only once the target acronyms were directly fixated.

The phonological convention for the article an to be followed by a word beginning with a vowel as opposed to a consonant represents an interesting and potentially understudied way in which to consider a word's sentential fit. ${ }^{4}$ In the case of the studies discussed above a word's sentential fit was generally determined by constraints generated on the basis of the sentence's global meaning and structure. On the other hand, using our manipulation, word $n+2$ 's lack of fit into the sentence is entirely determined by only the preceding word. Secondly, in order for readers to determine whether a word is implausible or violates syntactic expectations it is necessary for readers to reach a reasonably advanced stage of lexically processing this word, since they must retrieve its syntactic class and meaning from the mental lexicon. With our manipulation this is not the case; readers can determine a violation of the grammatical convention purely on the basis of the orthographic/phonological form of the following noun. Due to these two factors, it might be possible for participants to detect a violation of this phonological convention rapidly enough that it appears as an $n+2$ preview effect in the eye-movement record. Such an effect would have important implications for the extent to which people process information in the parafovea, and furthermore, the time-course across which they attempt to integrate words into a larger sentence representation. Both of these

\footnotetext{
${ }^{3}$ It might seem strange that we did not simply include this condition in Experiment 1. Frankly, given the size of prior $n+2$ preview effects, we did not expect it to be possible to observe reliably different $n+2$ preview effects for different $n+2$ preview types, and instead intended to focus upon the skipping of an depending on the following word's initial character. However, upon examination of the reading time data in Experiment 1 we concluded that it would be worth conducting a further experiment, including this third condition.

${ }^{4}$ To the best of our knowledge, beyond the work of Slattery et al. (2006) the relationship between an and the initial letter of the following word has primarily been examined in relation to the issue of form prediction in electrophysiological studies of language processing (e.g. see DeLong et al., 2005; Ito et al., 2016).
} 
issues hold relevance for current computational models of eye-movement control. In the current paper we focus on the E-Z Reader model (e.g. Reichle et al., 2006; Reichle et al., 2009) due to the fact that it contains parameters relating to both parafoveal processing and the integration of identified words into a sentence representation, something in which it is currently unique.

\subsection{The E-Z Reader model of eye movement control}

An important framework in which parafoveal processing and our study can be viewed is the E-Z Reader model of eye movement control. The E-Z Reader model explains eye movement behaviour using a relatively parsimonious set of parameters, focusing on how readers process individual words, how attention is directed to each visually available word, how readers make and execute saccade programming decisions, and how words are integrated into a higher level sentence representation. Within E-Z Reader it is assumed that readers lexically process one word at a time, with the processing of each word split into two phases $\left(\mathrm{L}_{1}\right.$ and $\left.\mathrm{L}_{2}\right)$. The durations of these stages are modulated by the frequency and predictability of each word. Upon completing $L_{1}$, readers begin programming a saccade to the next word, while continuing to process the fixated word in the $\mathrm{L}_{2}$ stage. Saccade programming is divided into two stages, with a labile stage (during which the saccade can be cancelled) lasting $\sim 125 \mathrm{~ms}$, and a non-labile stage (during which the saccade cannot be cancelled) lasting $\sim 25 \mathrm{~ms}$. During saccadic programming, several other processes are ongoing. First, the $\mathrm{L}_{2}$ stage of processing the fixated word will be completed, resulting in access to semantic information about the target word. At this point, the fixated word is integrated into the sentence representation while readers begin processing the parafoveal word in the $\mathrm{L}_{1}$ stage; thus, according to $E-\mathrm{Z}$ Reader integration should only occur once words are fully identified. Two things can happen at this point. First, the labile stage of programming a saccade to the parafoveal word may complete prior to $\mathrm{L}_{1}$ for this word; in this case, the parafoveal word is directly fixated. Alternatively, the $\mathrm{L}_{1}$ stage can complete for the parafoveal word prior to the saccade program becoming non-labile; at this point the saccade to word $n+1$ is cancelled, and a saccade is instead programmed to word $n+2$ - in other words, readers will skip the parafoveal word. Furthermore, if the processing of word $n+1$ completes from word $n$ then attention will move to word $n+2$ prior to a saccade being executed. Once readers fully program a saccade its execution takes approximately $25 \mathrm{~ms}$ to complete, and there is then a further $50 \mathrm{~ms}$ lag before new visual information propagates to the brain; consequently, readers continue processing the visual information extracted during a particular fixation for $\sim 75 \mathrm{~ms}$ after the eye leaves that position.

E-Z Reader explains basic preview effects through the fact that attention shifts to the parafoveal word before a saccade program is executed, and before visual information from the post-boundary fixation becomes available for processing. While the model does not make any explicit predictions about exactly why certain types of incorrect previews result in shorter fixation durations than others, the assumption has generally been based around a trans-saccadic activation account. As mentioned, such an account cannot explain effects of the contextual fit of a previewed word on subsequent fixations on an unrelated target word. Instead, these effects may require an alternative mechanism, which has been put forward by Schotter and colleagues in the form of forced fixations (Schotter, 2018; Schotter \& Leinenger, 2016; Schotter et al., 2018; Schotter et al., 2019). Forced fixations refer to instances in which readers complete the $\mathrm{L}_{1}$ stage of processing a word parafoveally, but after the saccade program towards this word becomes non-labile. In such cases it would make sense for readers to cancel the saccade to word $n+1$, and instead program one to word $n+2$. Unfortunately, this is not possible. Consequently, readers are forced to fixate word $n+1$. Schotter and colleagues argue that in these cases readers will pre-initiate a saccade from word $n+1$ to word $n+2$ prior to the eye landing on word $n+1$. In such cases the fixation on word $n+1$ will be entirely driven by the characteristics of the parafoveally previewed word as opposed to the foveally viewed target word, with readers not extracting new information from the now fixated word on the assumption that they have already identified it.

The contextual fit preview effects discussed above can be explained on the basis of forced fixations and, in our view, E-Z Reader's sentential integration parameters. In cases when readers make a forced fixation due to identifying a parafoveal preview of word $n+1$ as word $n+1$ itself, they should, during the course of the forced fixation, attempt to integrate this previewed word into their sentential representation. In cases when this previewed word is plausible in the sentential context this integration should be unproblematic, and as such the pre-programmed saccade away from this word should not be cancelled, resulting in relatively short fixations on the word. On the other hand, when the previewed word is either implausible or syntactically illegal in the sentence context, integrating that word into the sentence representation is likely to rapidly fail, resulting in the cancellation of the saccade away from this word, and further time spent fixating on the word, as well as potential regressions to earlier portions of the text. Hypothetically, this can explain contextual fit preview effects, although simulations with $E$-Z Reader may be necessary to assess this. It is worth noting that efforts have also been made to explain contextual fit preview effects through the idea that plausible words are easier to lexically process than implausible words, resulting in a greater number of forced fixations on plausible words, with these fixation being shorter than normal fixations. Due to this, average reading times are shorter on plausible than implausible words, due to lexical processing rather than integration processes.

E-Z Reader is able to explain $n+2$ preview effects through the idea that lexical processing will sometimes complete on word $n+1$ prior to the eye making a saccade across the invisible boundary, and the time it then takes for visual information from a post-boundary fixation to propagate through the visual system. While this should be a relatively rare occurrence, it does still happen often enough to explain some level of $n+2$ preview effects.

In terms of how often both $n+2$ processing and forced fixations should occur according to E-Z Reader, a set of simulations run by Schotter et al. (2014) are informative. Schotter et al. tested how often readers should commence the $L_{2}$ stage of processing word $n+1$ and $n+2$ parafoveally, and how often readers should process word $n+2$ at all. These simulations suggested that participants should proceed to the $\mathrm{L}_{2}$ stage of parafoveally processing word $n+1$ in $8 \%$ of instances, ${ }^{5}$ that they should process word $n+2$ in about $20 \%$ of trials, and that they should never proceed to the $\mathrm{L}_{2}$ stage of parafoveally processing word $n+2$. While these simulations do not give exact estimates of the prevalence of forced fixations, they do give an upper estimate, in that such fixations should not occur unless participants proceed beyond $L_{1}$ in processing the parafoveal word. One thing that drops out of these simulations is that forced fixations should not occur for word $n+2$ and that, as such, contextual fit preview effects should not be observed for these words.

Returning to our own manipulation, the above consideration of E-Z Reader should make several things clear. First of all, due to simulations suggesting that readers should never proceed beyond the $\mathrm{L}_{1}$ stage of processing word $n+2$ any effect of our manipulation would be highly surprising in current frameworks, due to the lack of potential forced fixations on word $n+2$. Secondly, it is interesting to consider more generally at what stage of processing within the model one would expect participants to detect the type of phonological violation used in the

\footnotetext{
${ }^{5}$ This outcome was obtained when the length of word $n+1$ was set to five letters and its frequency per million to 2019. An alternative simulation with frequency set to one per million and length to eight letters resulted in estimate of participants proceeding to $\mathrm{L}_{2}$ on $2 \%$ of trials; we report the simulation we do due to it seeming to represent more realistic lexical characteristics.
} 
current study. Arguably, the most logical point for this to occur would be at the point in which readers attempt to integrate the word into the representation of the sentence. However, as mentioned above it is also possible for readers to detect our violation much earlier than typical syntactic or semantic violations, with ours being based upon a low-level characteristic of the target word that does not require substantial lexical processing. As such, whether or not we observe an effect of our manipulation will be informative as to whether readers delay the phonological integration of an article with the following word until after lexical processing is completed for both words, or if such effects occur in an earlier, pre-lexical integration stage. We return to this issue in the General Discussion.

\section{Experiment 1}

In Experiment 1 we presented participants with sentences in which the indefinite article an was followed by a proper noun (e.g. English). We used the boundary paradigm to present readers with either a correct preview of this noun, or an incorrect preview that began with a consonant (e.g. Spanish) up until readers made a saccade into the space preceding an. Hence, in our design word $n+1$ was always an, and word $n+2$ was always a proper noun which was either compatible or incompatible with the preceding article until readers had begun to execute a saccade to either fixate or skip an. We chose to use proper nouns as our target word in order to increase the salience of the information representing the grammatical violation (i.e., the identity of the first letter of the word following an).

The main issue we were interested in examining in Experiment 1 was whether the low-level violation of an English phonological convention resulted in the reduced skipping of the article an. As discussed above, several researchers (e.g. Brothers \& Traxler, 2016; Veldre \& Andrews, 2018a) have recently found that word $n+1$ is less likely to be skipped when it is either syntactically illegal or implausible in the preceding sentence context. While readers should be no less likely to begin programming a saccade to skip an when it is followed by a consonant-initial word, it may be the case that upon shifting attention to word $n+2$ and detecting a violation this saccade may be cancelled. It actually seems fairly unlikely that participants would become aware of our manipulation quickly enough for this saccade to be cancelled regularly enough to result in reliable effects upon skipping. None-theless, such a finding seems potentially interesting enough for it to be worth testing this possibility.

More generally, we were also interested in testing whether our manipulation resulted in $n+2$ preview effects, and whether these effects are larger than in prior studies. Given the use of a shorter word $n+1$ than in other studies, as well as a capitalised word $n+2$, it seems likely that we should observe such effects.

\subsection{Method}

\subsubsection{Participants}

Sixty native speakers of English (39 females; mean age $=21.50$ ) with normal or corrected to normal vision participated for $£ 6$.

\subsubsection{Apparatus}

Eye movements were tracked using a tower-mounted SR Research Eyelink 1000. Sentences were displayed on a single line of a CRT monitor running at $120 \mathrm{hz}$. Viewing distance was $70 \mathrm{~cm}$, with $1^{\circ}$ of visual angle containing 2.7 characters of courier new font.

\subsubsection{Materials and design}

We constructed thirty sentences containing the indefinite article in the form an followed by a proper noun beginning with a vowel (e.g. English). Each proper noun was paired with an alternative proper noun beginning with a consonant sound (e.g. Spanish), rendering an the inappropriate form of the indefinite article. The two nouns were matched for length on an item-by-item basis. In addition, paired $t$-tests showed no significance differences between the two nouns in mean log bigram frequency $(\mathrm{t}(29)=-1.24, p=0.22$; consonant-initial mean $=2.03$, vowel-initial mean $=2.16$ ), mean log trigram frequency $(\mathrm{t}(29)=0.04$, $p=0.97$; consonant-initial mean $=0.83$, vowel-initial mean $=0.83$ ). Stimuli for both Experiment 1 and Experiment 2 can be found at https://osf.io/5sq8g/.

The boundary paradigm was used to present participants with the vowel-initial noun on $50 \%$ of trials and the consonant-initial noun on $50 \%$ of trials. The boundary was placed at the beginning of the space preceding an. As the eye crossed the invisible boundary the noun would always change to the vowel-initial version, such that participants always read a legal sentence.

\subsubsection{Procedure}

Participants provided informed consent upon arrival. Readers' heads were stabilized using a head rest. A three-point horizontal calibration grid was used, with the calibration being accepted if average error was below 0.30 degrees. Before each trial, there was a drift check in the centre of the screen, then a drift check on the left of the screen, and then a gaze contingent box in the same position as the sentence's first character. Participants were recalibrated if either drift check returned a value greater than 0.40 on two consecutive trials or they failed to trigger the gaze contingent box. Participants pressed a button after reading each sentence. Yes/no comprehension questions were presented following one third of the sentences; participants answered using the left or right mouse button. The experiment lasted approximately $30 \mathrm{~min}$.

\subsection{Results}

We analysed reading behaviour across two interest areas. The first was the word an, for which we examined skipping probability only. The second interest area was the previewed noun, on which we examined first fixation duration (i.e., the duration of the first fixation on this word), gaze duration (i.e., the total time between first fixating the word and making a saccade to another region), go-past time (i.e., the total time between first fixating the word and exiting the word to the right), and the probability of participants making a first-pass regression out. For fixation time measures, values more than 3 standard deviations from the grand mean of the untransformed data were removed, resulting in a maximum of 28 observations being removed from the data. Outlier removal was performed on a measure by measure basis, such that we did not necessarily remove a data point which was an outlier in one measure for all other measures. Means for these measures are shown in Table 1. Statistical analyses were conducted on log-transformed measures.

Prior to analysis we used SR-Research Data Viewer to 1) remove fixations above $800 \mathrm{~ms}$; 2) merge fixations below $80 \mathrm{~ms}$ with fixations less than 0.5 degrees of visual angle away; and 3) merge fixations below $40 \mathrm{~ms}$ with fixations less than 1.25 degrees away. These values represent the default settings within Data Viewer for fixation cleaning in reading studies. $0.75 \%$ of fixations across the whole experimental session were affected by the merging operation. We removed trials in which participants blinked on either the word an or the critical noun.

Table 1

Mean (Standard Error) Skipping Probability of "an" and Fixation Times and Regression Probabilities on Word $n+2$.

\begin{tabular}{lll}
\hline & Identity/vowel & Violation/consonant \\
\hline An skipping & $0.67(0.02)$ & $0.68(0.02)$ \\
First fixation duration & $225(2.34)$ & $235(2.38)$ \\
Gaze duration & $275(4.49)$ & $289(4.42)$ \\
Go-past time & $321(6.25)$ & $343(6.12)$ \\
Regressions out & $0.13(0.01)$ & $0.17(0.01)$ \\
\hline
\end{tabular}


We also removed trials in which the display change triggered early for our analysis of reading behaviour on an and the critical noun, and trials in which the display change completed more than $10 \mathrm{~ms}$ late for fixations on the previewed noun. ${ }^{6}$ These exclusions accounted for $11 \%$ of data for an and $13 \%$ of data for the previewed noun.

We constructed Bayesian linear mixed models to analyse our data. There are two main reasons we took a Bayesian approach in the current study. First, one of our main points of interest in Experiment 1 was the skipping of the article an. It seemed likely at the outset that we may have to argue in favour of a null hypothesis for this measure, and as such an analysis that allows us to do so was an obvious choice. The Bayesian LMMs had a prior of $\operatorname{Normal}(\mu=0, \sigma=10)$ for the model intercept and $\operatorname{Normal}(0,1)$ for the effect of preview type, with a regularization of 2 on the covariance matrix of random effects. These priors are weakly informative, and take account of the fact we analysed log-transformed data. Each model was run with two chains of 2000 iterations each. The Rhat value for each parameter in each model was equal to 1 , indicating successful model convergence. For each analysed measure we report a mean effect estimate, the upper and lower bounds of a $95 \%$ credible interval, and the probability that the effect of our preview manipulation was greater than 0 . This output is displayed in Table 2. Data files and R Scripts for analysing them can be found at https://osf.io/5sq8g/.

Our manipulation had very little effect on the skipping of an. On average, participants would skip this word on $67 \%$ of trials given a vowel preview, and $68 \%$ of trials given a consonant preview. The output from our model suggests that the probability of our effect being larger than a value of zero is only 0.772 ; as such we have very little evidence that the skipping of an was influenced by the initial letter of the following word. Furthermore, the trend was actually in the opposite direction to our initial hypothesis.

Our statistical models suggested that we had evidence in favour of an effect of our preview manipulation upon fixation behaviour on the target noun, with mean effects estimates of $9 \mathrm{~ms}$ in first fixation duration, $16 \mathrm{~ms}$ in gaze duration, $25 \mathrm{~ms}$ in go-past time, and a $4 \%$ increase in the probability of participants making a regression back to earlier parts of the text.

\subsection{Discussion}

In Experiment 1 we tested whether participants a) extracted information from a parafoveal preview of word $n+2$ during fixations on word $n$ and $b$ ) whether the extraction of this information affected the skipping of the intervening article an due to a grammatical violation. We did this by presenting participants with previews of word $n+2$ which were either correct, or which were incorrect and violated the convention for the indefinite article an to be followed by a word beginning with a vowel sound. Readers were clearly extracting some information from word $n+2$ in the parafovea, with our Bayesian models showing preview effects across all measures examined on word $n+2$. In contrast, our manipulation had minimal effects on the skipping of word $n+1$.

It is clearly not the case that our lack of skipping effect was due to participants failing to extract information from word $n+2$ while still fixated on word $n$. Had this been the case then our manipulation should also have had no effect on reading times on word $n+2$. Rather, we suspect that word $n+2$ was simply processed too late for it to have any effect on the programming of a saccade which was supposed to either skip or land on an. We will leave any further discussion of this effect until our General Discussion, after we present additional data relating

\footnotetext{
${ }^{6}$ Adopting a stricter exclusion criteria and excluding any trials in which the display change occurred during a fixation made no difference to our pattern of effects, nor what was considered reliable and unreliable in either Experiment 1 or Experiment 2.
}

to this issue in Experiment 2.

One surprising aspect of our data was the size of the $n+2$ preview effect on fixation durations on word $n+2$ itself. Our effects were relatively large compared to the estimated effect size from Vasilev and Angele's (2017) meta-analysis. Specifically, our effect was $9 \mathrm{~ms}$ in first fixation durations and $16 \mathrm{~ms}$ in gaze durations, whereas when Vasilev and Angele focused on studies using a shorter word $n+1$ they found effects of $2.3 \mathrm{~ms}$ and $6.9 \mathrm{~ms}$ in these measures. Thus, there is presumably something about our manipulation that resulted in these larger effects. We can think of three potential aspects of our stimuli and manipulation that drove this effect.

First, we used a two-letter word $n+1$, which is shorter than word $n+1$ has typically been in prior $n+2$ preview studies. Arguably, this should increase the probability of observing $n+2$ preview effects due to the low processing load of this word, ${ }^{7}$ and the fact that word $n+2$ will be in higher acuity vision and thus processed more efficiently. Second, we used a capitalised word $n+2$ in our experiment- prior research (e.g. Rayner \& Schotter, 2014) has shown that readers gain a larger preview effect from word $n+1$ when it is capitalised, and it would be unsurprising if the same was true of word $n+2$.

A final factor driving our larger preview effects, and the focus of Experiment 2, is the possibility that participants were in fact processing word $n+2$ to an extent that the violation preview was being detected by the reading system, leading to processing difficulties which did not appear until direct fixation on word $n+2$. Unfortunately, it is not possible to assess this possibility without data testing whether smaller $n+2$ effects are observed with a false preview which does not violate English inter-word phonological conventions. As such, it was necessary to run a further experiment.

\section{Experiment 2}

In order to further investigate our surprisingly large $n+2$ preview benefit from Experiment 1 we conducted Experiment 2. Specifically, we were interested in examining whether our large effect in Experiment 1 was in part due to the fact that the incorrect preview violated the typical use of the indefinite article an. To do so we presented readers with sentences in which they received either 1) an identity preview which followed the standard English convention (e.g. an Icelandic), an incorrect preview which violated this convention (e.g. an Mongolian), or an incorrect preview which followed standard grammatical conventions (e.g. an Ethiopian). Once again an invisible boundary was set before the indefinite article an such that the preview would change to the target word as readers' eyes moved towards it.

As well as wanting to test whether readers gain differential preview effects to these two preview types we wished to further investigate our (lack of) skipping effect from Experiment 1. We suspect that the nonreliable $2 \%$ estimated difference we observed in this experiment was most likely just noise, as opposed to a real effect which we lacked the power to detect in Experiment 1. We will be able to use the data from Experiment 2 to test this possibility in two ways. First of all, we can examine whether we observe a similar trend in Experiment 2, and then combine the data from our two experiments to test for an effect with considerably more statistical power than in either individual experiment.

\subsection{Method}

\subsubsection{Participants}

78 native speakers of English (61 female; mean age $=21.64$ ) with

\footnotetext{
${ }^{7}$ It should be noted that this explanation relies on the same logic as findings showing that foveal load affects the size of $n+1$ preview effects, which recent evidence (Veldre \& Andrews, 2018b) suggests may not be as robust of an effect as often assumed.
} 
Table 2

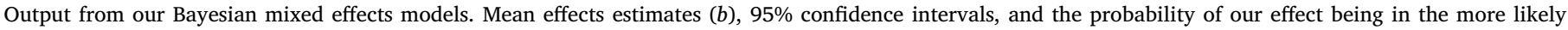
direction are reported. Log-units output by the model are reported, followed by values translated into fixation times and probabilities in parentheses.

\begin{tabular}{|c|c|c|c|c|c|}
\hline & Intercept & $B$ & L95\% & U95\% & $\mathrm{P}(b>/<0)$ \\
\hline An skipping & $0.77(0.68)$ & $0.10(2 \%)$ & $-0.16(-4 \%)$ & $0.37(7.4 \%)$ & 0.772 \\
\hline FFD & $5.40(221)$ & $0.04(9)$ & $0.01(2)$ & $0.08(18)$ & 0.994 \\
\hline GD & $5.56(260)$ & $0.06(16)$ & $0.00(0)$ & $0.13(36)$ & 0.977 \\
\hline GP & $5.69(296)$ & $0.08(25)$ & $0.01(3)$ & $0.15(48)$ & 0.991 \\
\hline Regs. out & $-2.00(0.12)$ & $0.34(4 \%)$ & $-0.01(-0 \%)$ & $0.70(9 \%)$ & 0.973 \\
\hline
\end{tabular}

normal or corrected to normal vision participated for $£ 6$. An additional 6 participants were tested, but their data was excluded due to them either noticing more than five display changes or poor tracking.

\subsubsection{Apparatus}

Apparatus were identical to Experiment 1 . A slightly smaller font was used to accommodate items from an experiment run concurrently; $1^{\circ}$ of visual angle contained 3.4 characters of courier new font.

\subsubsection{Materials and design}

We constructed forty-two sentences containing the indefinite article in the form an followed by a proper noun beginning with a vowel (e.g. Icelandic). Fourteen of these sentences were identical to those used in Experiment 1. Each proper noun was paired with two alternative proper nouns, one beginning with a consonant sound (e.g. Mongolian) and the second beginning with a vowel sound (e.g. Ethiopian). The three words were matched for length on an item-by-item basis.

In addition, we also matched the words on average on a number of variables. First, we ensured that the two false previews did not differ significantly in terms of their level of orthographic overlap with the target word $(\mathrm{t}(41)=0.23, p=0.82)$. This was calculated in terms of the Levenshtein distance between each preview word and the target word. We also ensured that the incorrect vowel-initial preview never shared an initial letter with the target word. There were also no significant differences between the three words in terms of mean log trigram frequency (all $p>0.4$ ), mean log bigram frequency (all $p>0.2$ ), or log frequency per million in the British National Corpus (all $p>0.5$ ). Means for each of these variables can be found in Table 3. It should be noted that a large number of vowel-initial proper nouns were used as both correct previews and incorrect-vowel previews, due to the fact that there are a limited number of such proper nouns to use.

The boundary paradigm was used to present participants with the vowel-initial preview on one third of trials, the consonant-initial preview on one third of trials, and the target word on the remaining third of trials. The boundary was placed at the beginning of the space preceding an. As the eye crossed the invisible boundary the noun would always change to the vowel-initial target word, such that participants always read a legal sentence.

\subsubsection{Procedure}

The procedure was identical to Experiment 1.

\subsection{Results}

We prepared our data for analysis in an identical way to Experiment

Table 3

Characteristics of the stimuli used in Experiment 2.

\begin{tabular}{llll}
\hline & Identity & Consonant & Vowel \\
\hline Levenshthein distance from target & 0 & 6.14 & 6.11 \\
Mean log trigram frequency & 0.85 & 0.91 & 0.82 \\
Mean log bigram frequency & 1.98 & 1.97 & 2.07 \\
Log frequency per million (BNC) & 1.59 & 1.72 & 1.61 \\
\hline
\end{tabular}

Table 4

Mean (Standard Error) Skipping of the Article An, and Reading Measures for Word $n+2$ in each Preview Condition.

\begin{tabular}{llll}
\hline & Identity & Vowel & Consonant \\
\hline An skipping & $0.64(0.02)$ & $0.64(0.02)$ & $0.67(0.02)$ \\
FFD & $221(2.21)$ & $226(2.30)$ & $233(2.47)$ \\
GD & $271(4.21)$ & $277(4.15)$ & $284(4.48)$ \\
Go-Past & $325(6.42)$ & $340(6.67)$ & $365(7.22)$ \\
Regression out & $0.16(0.01)$ & $0.17(0.01)$ & $0.23(0.01)$ \\
\hline
\end{tabular}

1 , and analysed the same measures in the same regions. $0.88 \%$ of fixations across the whole experimental session were affected by the merging operation in Data Viewer. Exclusions due to blinks and display change errors accounted for $17 \%$ of the data for an, and $20 \%$ of data for the previewed noun. Outlier cleaning resulted in a maximum of 54 observations being removed for any one measure. Means can be seen in Table 4, and model output in Table 5. The Rhat value for each parameter in each model was equal to 1 , indicating successful model convergence.

\subsubsection{Word $n+1$ skipping}

For skipping behaviour on the word an we used the default contrast structure in $\mathrm{R}$, with the consonant preview set as the baseline. Thus, this model returned two contrasts, with one checking whether skipping differed in the identity preview condition relative to the consonant preview condition, and the second checking whether skipping differed in the vowel preview condition relative to the consonant preview condition. Numerically, there was a trend for participants to skip an more when it was followed by a word beginning with a consonant, similarly to Experiment 1 . However, this effect was not reliable in either contrast in the model.

As mentioned above, it is possible to combine the data from the current experiment with the data from Experiment 1, in order to test whether the initial character of word $n+2$ affected the skipping of an. We constructed a Bayesian logistic mixed model with a fixed effect testing for the effect of whether the preview of $n+2$ started with a vowel or a consonant; we did not discriminate between cases in which word $n+2$ was a false preview beginning with a vowel and cases in which word $n+2$ was the correct preview beginning with a vowel. This model suggested that participants would skip an more when it was followed by a consonant-initial word than a vowel-initial word; however, while the credible interval was smaller than in either of the models examining the data for Experiment 1 and Experiment 2 separately, it still included some estimates that the effect went in the opposite direction. The probability that the effect went in the direction of increased skipping with a consonant preview was 0.911 .

\subsubsection{Word $n+2$ reading}

For reading behaviour on word $n+2$ we used the default contrast structure in $\mathrm{R}$ for all models, with our intercept set to be the vowelinitial incorrect preview. As such, our model returned one comparison comparing trials in which participants received an identity preview with an incorrect preview which did not violate phonological conventions (henceforth referred to as the identity preview effect), and one 
Table 5

Output from our Bayesian Models for Experiment 2.

\begin{tabular}{|c|c|c|c|c|c|c|}
\hline & & Intercept & $B$ & L95\% & U95\% & $\mathrm{P}(b>/<0)$ \\
\hline \multirow[t]{3}{*}{ An skipping } & Identity contrast & $0.74(68 \%)$ & $-0.10(-2 \%)$ & $-0.33(-8 \%)$ & $0.10(2 \%)$ & 0.843 \\
\hline & Vowel contrast & $0.74(68 \%)$ & $-0.11(-2 \%)$ & $-0.32(-7 \%)$ & $0.11(2 \%)$ & 0.821 \\
\hline & Composite model & $0.71(67 \%)$ & $-0.10(-2 \%)$ & $-0.26(-6 \%)$ & $0.05(1 \%)$ & 0.911 \\
\hline \multirow[t]{2}{*}{ FFD } & Identity contrast & $5.38(217 \mathrm{~ms})$ & $-0.02(-4 \mathrm{~ms})$ & $-0.05(-11 \mathrm{~ms})$ & $0.01(2 \mathrm{~ms})$ & 0.911 \\
\hline & Violation contrast & $5.38(217 \mathrm{~ms})$ & $0.03(6 \mathrm{~ms})$ & $-0.00(-0 \mathrm{~ms})$ & $0.06(13 \mathrm{~ms})$ & 0.951 \\
\hline \multirow[t]{2}{*}{ GD } & Identity contrast & $5.54(255 \mathrm{~ms})$ & $-0.03(-8 \mathrm{~ms})$ & $-0.07(-17 \mathrm{~ms})$ & $0.01(3 \mathrm{~ms})$ & 0.928 \\
\hline & Violation contrast & $5.54(255 \mathrm{~ms})$ & $0.01(3 \mathrm{~ms})$ & $-0.03(-8 \mathrm{~ms})$ & $0.05(13 \mathrm{~ms})$ & 0.648 \\
\hline \multirow[t]{2}{*}{ GP } & Identity contrast & $5.71(302 \mathrm{~ms})$ & $-0.05(-15 \mathrm{~ms})$ & $-0.10(-28 \mathrm{~ms})$ & $-0.00(-0 \mathrm{~ms})$ & 0.980 \\
\hline & Violation Contrast & $5.71(302 \mathrm{~ms})$ & $0.05(15 \mathrm{~ms})$ & $0.01(3 \mathrm{~ms})$ & $0.10(31 \mathrm{~ms})$ & 0.988 \\
\hline \multirow[t]{2}{*}{ Reg. out } & Identity contrast & $-1.79(14 \%)$ & $-0.09(-1 \%)$ & $-0.41(-4 \%)$ & $0.22(3 \%)$ & 0.724 \\
\hline & Violation contrast & $-1.79(14 \%)$ & $0.40(6 \%)$ & $0.10(1 \%)$ & $0.69(11 \%)$ & 0.998 \\
\hline
\end{tabular}

contrast comparing trials in which participants received an incorrect preview which did not violate grammatical conventions with trials in which participants received an incorrect preview which did violate grammatical conventions (henceforth referred to as violation preview effect).

There was a trend in all measures for an identity preview effect, such that participants would read word $n+2$ faster given a correct preview. Our linear mixed models suggested that we had clear evidence for this effect in go-past times, although the evidence in first fixation durations and gaze durations was less clear. It should be noted that this does not constitute a failure to replicate Experiment 1, since the relevant contrast here would be between the identity preview and the consonant-initial preview.

More interestingly, there was also a trend for a violation preview effect in all measures, such that participants would make shorter fixations on a word given an incorrect vowel-initial preview than an incorrect constant-initial preview. This effect was clear in go-past times and the probability of participants making a first pass regression out of word $n+2$, suggesting that the effect was mainly driven by re-reading behaviour.

A final issue worth considering is the extent to which our effects were dependent upon readers skipping the article an. In order to assess this we repeated our analysis, looking only at trials in which readers did in fact skip an. In this sub-set of our data our effects were numerically larger, such that reading times on word $n+2$ were $11 \mathrm{~ms}, 16 \mathrm{~ms}$, and $33 \mathrm{~ms}$ longer given a violation preview as opposed to an incorrect vowel preview in first fixations, gaze durations, and go-past times, respectively. Our Bayesian models suggested evidence in favour of these effects in both first fixation duration $(\mathrm{P}(b>0)=0.975)$ and go-past times $(\mathrm{P}(b>0)=0.999)$, although, surprisingly, not gaze duration ( $\mathrm{P}$ $(b>0)=0.880)$. Thus, our effects were numerically larger when readers did skip the word an, although the statistical evidence for these effects was still less robust in early measures as compared to later measures. $^{8}$

\subsection{Discussion}

In Experiment 2 we primarily set out to test whether readers obtained a preview effect from word $n+2$ driven by the violation of an inter-word phonological rule. The key comparison for assessing such an effect was in whether participants experienced greater processing difficulty when given a false preview beginning with a consonant as opposed to a false preview beginning with a vowel. We observed such

\footnotetext{
${ }^{8}$ It could also be asked whether there were any earlier effects of our manipulation, which appeared either in the rare occurrences when participants did fixate word $n+1$ prior to word $n+2$, or even during fixations prior to the eye crossing our invisible boundary. A set of extra analyses conducted to test this possibility revealed very little evidence in favour of earlier effects. A more detailed discussion of these analyses can be found in the appendix.
}

evidence, finding that participants were more likely to make a regression out of word $n+2$ following a consonant-initial preview, with this resulting in longer go-past times for this word. While there were trends in a similar direction on earlier measures of processing (first fixation duration; gaze durations) there was not strong evidence in favour of the effect in our statistical model, although there was evidence for an effect in first fixation durations when we limited our analysis to cases in which an was skipped. Thus, it seems that any processing difficulty primarily resulted in greater re-reading times of earlier portions of the sentence as opposed to identification difficulty of the previewed word. This could be considered surprising; in general preview effects tend to produce reliable effects in the earliest measures of word fixation time, and it would be considered unusual for these effects to only emerge in measures taking re-reading of the sentence into account. However, this pattern makes more sense when considering the likely locus of our effect. Typically, preview effects are due to one preview activating the target word to a greater extent than another preview, resulting in less time being needed to identify that word. In these cases it makes sense that early measures of reading time would be affected, since these measures can be viewed as more of an index of word identification. However, in our study, as we discuss in more detail below, the likely locus of our effect is the rapid detection of a grammatical violation, thus explaining why our manipulation seemed to have more of an effect on re-reading behaviour as opposed to word fixation time.

\section{General discussion}

In the current study, we set out to test whether readers would detect a violation of the English convention for the indefinite article an to be followed by a word beginning with a vowel sound (e.g. Icelandic) as opposed to a consonant sound (e.g. Mongolian) while both of these words were still in the parafovea. Across our two experiments we examined whether such violations resulted in a) the reduced skipping of $a n$ and $\mathrm{b}$ ) whether reading times of word $n+2$ were increased given a violation preview of this word. The answer to the first of these question is clearly no. In all three relevant comparisons for assessing this issue we actually observed a trend towards an effect in the opposite direction, such that participants would skip an more given a violation preview than any other preview type, with our combined analysis of the data from Experiment 1 and 2 suggesting that there was a 91\% chance that the observed effect was in the opposite direction to our hypothesis. While this level of probability does not indicate strong evidence for the effect, we will return to this counterintuitive trend further below. Our reading time data showed a pattern of effects more in line with what we hypothesised, such that participants seemed to encounter a greater level of processing difficulty when given a violation preview than a grammatical preview. This effect mainly emerged in later measures of processing, such as go-past time and the probability of participants making a regression back to earlier parts of the text. We will primarily focus on these effects for the rest of this discussion.

As discussed above, one way of explaining previous contextual fit 
preview effects is in terms of readers identifying a word on the basis of its parafoveal preview, but having to fixate this word anyway due to it no longer being possible to cancel the saccade towards it, and then attempting to integrate this identified word into the sentence representation during the forced fixation. When this word cannot be integrated, a saccade from the parafoveal word will be cancelled, resulting in increased reading times for that word. This explanation of such effects for word $n+1$ already relies on very few instances of eye movement behaviour ( $\sim 8 \%$ in Schotter et al., 2014) and some researchers have already questioned whether these limited instances can explain their contextual fit preview effects (e.g. Veldre \& Andrews, 2018a; Andrews \& Veldre, 2019). These instances should be even rarer for studies of $n+2$ preview effects, and as such, we see very little room for explaining our effects within this framework as it is, although acknowledge that future simulations with $E$-Z Reader may end up contradicting our position. Instead, we favour an account in which, in certain cases, readers will attempt to at least partially integrate a word that has not yet been fully identified into the sentence, or at least with certain other words in the sentence. To be clear, we are not proposing that all integrative processes happen in parallel with lexical processing; rather, we merely intend to argue that when certain aspects of a word's fit within the sentence can be assessed on the basis of lower-level information then readers will take advantage of this. As such, it is not our intention to claim that E-Z Reader's assumptions about integrating multiple words within a sentence together are fundamentally incorrect; rather, we are advancing the position that as such models are further developed, a greater level of nuance will be required in terms of what would be a pre-lexical as opposed to post-lexical integration process.

Quite how early this early integration might have occurred in the current study can be viewed in terms of the framework provided by E-Z Reader. We consider the sequence of events to have proceeded as follows. First, while fixated on word $n$ readers would often manage to fully identify both word $n$ and word $n+1$, and subsequently integrate these identified words into the sentence. At this point attention would have moved onto word $n+2$ as a saccade continued to be programmed towards this word. It seems unlikely that the reading system detected the grammatical violation prior to this saccade program becoming nonlabile, otherwise we would have observed decreased skipping of an. Rather, we believe that our manipulation must have affected the reading system at some point between the time at which the saccade towards word $n+2$ became non-labile, and when participants gained access to visual information extracted upon direct fixation on word $n+2$. As participants detected the grammatical violation they would instantly have begun programming a regression out of the target word on the basis of the preview information on a proportion of trials, resulting in both higher regression probabilities and increased go-past times for our target words, in the absence of reliable first-pass reading effects.

It is briefly worth considering whether our manipulation could actually be explained in a trans-saccadic activation account of preview effects, as opposed to a contextual fit account. It is possible that such an account could explain our effect at a basic level, in that participants may be experiencing a phonological preview effect (Ashby \& Rayner, 2004; Ashby et al., 2006; Chace et al., 2005; Miellet \& Sparrow, 2004; Pollatsek et al., 1992). In this account, readers would have gained a preview benefit on the basis of the target word being primed by a word beginning with an initial phoneme which is either more (i.e. a vowel) or less (i.e. a consonant) concordant with this target word. There are a number of reasons why we view this as an unlikely account of our findings. First, it seems unlikely that such a small level of overlap between a preview and target should result in detectable processing time differences, even if this preview was presented as word $n+1$ rather than word $n+2$. Secondly, a recent Bayesian meta-analysis of phonological preview effects (Vasilev et al., 2019) suggests that these effects are far smaller than generally assumed, even for previews of word $n+1$. In this meta-analysis it was found that in studies of English the phonological preview effect amounts to about only $1.9 \mathrm{~ms}$ in first fixation duration and $4.5 \mathrm{~ms}$ in gaze duration. Unfortunately, the metaanalysis does not provide an estimate of the effect size in go-past time, for us to be able to assess whether it grows in a similar way in this measure as in our own study. However, if effects of previews with far higher phonological overlap with the target word are so small for word $n+1$, it would be highly surprising to find effects with word $n+2$ using a weaker manipulation of phonology. Finally, the evidence for our effect was strongest in measures taking regressions into account (i.e. regressions out of word $n+2$; go-past time), without particularly strong evidence in first-pass measures, although effects may have appeared in these measures with greater statistical power. Even ignoring whether effects were reliable in certain measures compared to others, there was a substantial increase in the numerical size of the effect in later measures (7 ms in gaze duration vs. $25 \mathrm{~ms}$ in go-past time). As alluded to in our Discussion of Experiment 2, this seems more in-line with an integration effect than a trans-saccadic activation effect. While it would be possible to discriminate between these two accounts by testing whether our preview effect is still observed when of is used in place of an (i.e. phonological difference remains without grammaticality difference) we consider the above reasons sufficient to proceed on the understanding that our effect is due to integration, while acknowledging that further empirical work may be required in the future to lend further weight to our arguments. This effect of integration would be consistent with theories of sentence processing that conceptualize comprehension as a form of perceptual cue integration based on inference wherein 'low-level' perceptual information cues the inference of 'higher-level' structure and where in turn, sentence context shapes the processing of incoming lower-level perceptual features (see Martin, 2016).

In order to further establish the time-course across which readers detect a violation between the indefinite article form and the following word's form, it may be possible to examine foveal as opposed to parafoveal processing of this word. For example, in order to demonstrate that readers do not perform syntactic integration of a word prior to completing lexical processing, Staub (2011) orthogonally varied whether a word was easy or difficult to identify through a frequency manipulation, and whether it was easy or difficult to integrate into the sentence through various syntactic manipulations. Staub argued in favour of the serial staged-architecture built into $E$-Z Reader on the basis that these two variables did not interact with each other. If we are correct that in the case of the an violation readers are attempting some basic level of integration pre-lexically, then we might find some form of interaction between these violations and the lexical processing difficulty of the target noun. Specifically, the violation may cause participants to terminate lexical processing of the noun early, thus resulting in a reduced frequency effect in violation as opposed to non-violation conditions.

A further issue worth considering is the extent to which our manipulation exerted its influence at a phonological level, as opposed to an orthographic level. In the former account the effect would have been due to readers converting the orthographic information into a phonological code, and detecting the violation through that, while in the former account readers would simply determine the violation on the basis of whether the letter is a vowel or consonant. In our study, the effects could have been due to either factor. One way of discriminating between these possibilities would be through the use of words beginning with the letter $u$, which is typically considered a vowel but will often be pronounced with a consonant sound. By testing whether violation effects are observed for constructions such as a Ukrainian compared to constructions such as an Ulsterman it would be possible to determine the extent to which phonology was used in the detection of our manipulation. It may also be possible to make use of acronyms in a similar manner to Slattery et al. (2006) to discriminate between a phonological and orthographic locus of our effect, although it is unclear whether the processing of these acronyms could be considered 
representative of other words.

As well as adding to a literature showing that readers assess the fit of a parafoveal word with preceding words in the sentence, our study also adds to a literature suggesting that people may sometime use (relatively) low-level information from words in order to assess their contextual fit. For example, Cutter et al. (2020b) recently demonstrated that people may use initial-letter capitalisation as a cue that an upcoming word is a proper noun prior to completing lexical processing of that word. In our study readers were seemingly assessing whether word $n+2$ was compatible with the preceding article on the basis of its orthographic form, with their being little chance that readers could have processed this word substantially enough for the effect to be postlexical.

One perplexing aspect of our data was the tendency for an to be skipped more as opposed to less when it was followed by a consonantinitial preview. This effect makes very little sense in any framework we can think of. Technically, it is possible to view a violation preview of word $n+2$ increasing the skipping of word $n+1$ as an attractor effect, whereby readers' eyes are drawn towards unusual information in the parafovea. However, in the case of our study the violation preview should only start to be considered unusual once participants have already fully identified the preceding word an. Presumably, if it was still possible for readers to cancel a saccade to an and program one towards word $n+2$ at this point in time, they would chose to do so regardless of whether there is something drawing their eye to word $n+2$. As such, it is not clear to us what mechanism may be responsible for this trend. It could be argued that one possibility is that readers were adopting a word-grouping strategy (e.g. see Radach, 1996), whereby they treated a short article and the following noun as a single perceptual unit when targeting saccades. In such cases, the perceptual pattern an followed by a consonant would be considered orthographically unusual, resulting in effects on where the eyes land on this two-word region, similarly to the effect of unusual orthography in a single word (e.g. White \& Liversedge, 2004). To our minds, this seems unlikely, especially when considering research contradicting the word-grouping hypothesis (e.g. Drieghe et al., 2008). None-the-less, further work may be necessary to determine if our effects could be explained in this framework.

Moving beyond our phonology effects, the current study also contributes to the growing literature examining $n+2$ preview effects during reading. In Experiment 1 we observed an $n+2$ preview effect that was larger than what has typically been observed in prior research, and in Experiment 2 we observed what is - to the best of our knowledge - the first instance of differential effects of two different incorrect $n+2$ previews, with prior studies only finding a difference between a correct vs. incorrect preview. Recall that it may be the case that the small $n+2$ preview effects observed in prior studies could be a consequence of display change awareness as opposed to pre-processing of information from the parafoveal word (e.g. Angele et al., 2016); our effects could not be explained in this way, given that readers responded differently to different types of preview. Thus, our study may constitute some of the strongest evidence available that readers process word $n+2$ during reading. It should be noted that in the current study we used target words beginning with a capitalised proper noun. It may be that this exaggerated the size of our effect relative to studies using lower-case nouns (see Rayner \& Schotter, 2014). Thus, future research may be necessary to test whether these effects replicate when using common nouns.

\subsection{Conclusion}

In closing, we investigated whether readers of English are sensitive to a relatively low-level inter-word phonological violation when this violation only appears in the parafovea. Our data suggest that this is the case, with longer target reading times in a violation condition than a non-violation condition. This effect suggests that readers may sometimes perform limited integration of an upcoming word into a sentence representation prior to the completion of lexical processing for that word, broadly consistent with a cue-based perceptual inference mechanism.

\section{CRediT authorship contribution statement}

Michael G. Cutter:Conceptualization, Methodology, Software, Formal analysis, Investigation, Resources, Data curation, Writing original draft, Writing - review \& editing.Andrea E. Martin:Conceptualization, Methodology, Writing - review \& editing, Supervision, Project administration, Funding acquisition.Patrick Sturt:Conceptualization, Methodology, Formal analysis, Writing - review \& editing, Supervision, Project administration, Funding acquisition.

\section{Declaration of competing interest}

None.

\section{Acknowledgements}

This research was supported by the Leverhulme Trust Research Project Grant [Grant number RPG-2017-049] awarded to PS and AEM, and was conducted while the first author was employed at the University of Edinburgh. AEM was supported by the Max Planck Research Group "Language and Computation in Neural Systems" and by the Netherlands Organization for Scientific Research [grant number 016.Vidi.188.029].

\section{Appendix A}

In the following appendix we present an additional analyses of our data, requested by a reviewer of an earlier version of our article. The purpose of this analysis was to test whether our effect appeared earlier than suggested by our main a priori analysis. Specifically, we examine whether preview type affected fixations made on the word prior to the invisible boundary or on the article an. We discuss the analysis for these additional regions for both Experiment 1 and Experiment 2 concurrently.

\section{A.1. Parafoveal-on-foveal effects}

An analysis looking at the reading of the word prior to the invisible boundary was conducted to detect any potential parafoveal-on-foveal effects of our manipulation. It may be that readers detected an unusual visual pattern between two parafoveal words (e.g. an $S$ ) and as such reading times on the pre-boundary word would be affected. To test for such effects we constructed Bayesian linear mixed models. In Experiment 1 these models compared the identity preview to the violation preview. In Experiment 2 one contrast compared the violation preview to the identity preview, while a second contrast compared the violation preview to the incorrect vowel preview. Mean reading times for Experiment 1 and 2 can be seen in Table A.1 and Table A.3, respectively, while the output of the Bayesian linear mixed models can be seen in Table A.2 and Table A.4, respectively. 
Table A.1

Mean (standard error) reading times on the word prior to the invisible boundary in Experiment 1.

\begin{tabular}{lll}
\hline & Identity/vowel & Violation/consonant \\
\hline First fixation duration & $217(2.44)$ & $216(2.39)$ \\
Gaze duration & $253(3.82)$ & $246(3.57)$ \\
Go-past time & $288(5.08)$ & $286(5.42)$ \\
Regressions out & $0.11(0.01)$ & $0.14(0.01)$ \\
\hline
\end{tabular}

Table A.2

Output from our Bayesian mixed effects models for Reading Times on the Word Prior to the Invisible Boundary in Experiment 1. Mean effects estimates (b), 95\% confidence intervals, and the probability of our effect being larger than zero are reported. Log-units output by the model are reported, followed by values translated into fixation times and probabilities in parentheses.

\begin{tabular}{|c|c|c|c|c|c|}
\hline & Intercept & $B$ & L95\% & U95\% & $\mathrm{P}(b>0)$ \\
\hline FFD & $5.33(206)$ & $0.00(0)$ & $-0.03(-6)$ & $0.03(6)$ & 0.523 \\
\hline GD & $5.44(230)$ & $-0.02(-4)$ & $-0.06(-13)$ & $0.02(5)$ & 0.124 \\
\hline GP & $5.56(260)$ & $-0.00(0)$ & $-0.05(-13)$ & $0.04(11)$ & 0.453 \\
\hline Regs. out & $-2.44(0.08)$ & $0.30(0.03)$ & $-0.16(-0.01)$ & $0.75(0.08)$ & 0.910 \\
\hline
\end{tabular}

Evidence for a parafoveal-on-foveal effect of our manipulation was limited. In Experiment 1 first fixation durations and go-past times were practically identical regardless of preview type. There was a numerical trend for gaze durations to be 7 ms longer given an identity preview, but the statistical evidence for this effect was weak $(\mathrm{P}(b>0)=0.124)$.

In Experiment 2, there were certain contrasts in our data that could be viewed as evidence for a parafoveal-on-foveal effect of our manipulation when considered in isolation, but not when considered alongside other contrasts within Experiment 2, as well as the data from Experiment 1. For example, in go-past time there was actually evidence for a difference between the identity condition ( $m=262 \mathrm{~ms}$ ) and the consonant preview condition $(m=275 \mathrm{~ms} ; \mathrm{P}(\mathrm{b}>0)=0.976)$; however, there was no equivalent difference between the consonant preview and the incorrect vowel preview $(m=272 \mathrm{~ms} ; \mathrm{P}(b>0)=0.652)$, which there presumably would have been if the effect was due to participants detecting the violation. In addition, the lack of an effect in this measure in Experiment 1, and the fact that the trend here was in the opposite direction, leads us to suspect the effect in this contrast from Experiment 2 may have been spurious. Again, there was very little in the way of a systematic difference between the conditions in either first fixation duration nor gaze duration. Thus, on balance, there seems to be very little evidence for an effect of our manipulation prior to readers crossing the invisible boundary.

Table A.3

Mean (standard error) reading times on the word prior to the invisible boundary in Experiment 2.

\begin{tabular}{llll}
\hline & Identity & Vowel & Consonant \\
\hline FFD & $206(2.28)$ & $207(2.20)$ & $210(2.16)$ \\
GD & $236(3.52)$ & $232(3.26)$ & $236(3.33)$ \\
Go-Past & $262(4.77)$ & $272(5.37)$ & $275(5.20)$ \\
Regression out & $0.09(0.01)$ & $0.12(0.01)$ & $0.12(0.01)$ \\
\hline
\end{tabular}

Table A.4

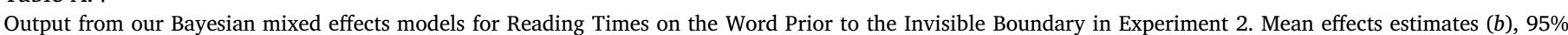

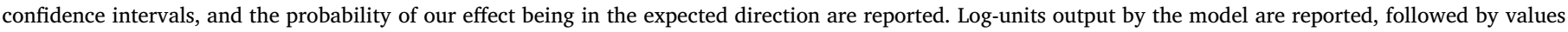
translated into fixation times and probabilities in parentheses.

\begin{tabular}{|c|c|c|c|c|c|c|}
\hline & & Intercept & $b$ & L95\% & U95\% & $\mathrm{P}(b>/<0)$ \\
\hline \multirow[t]{2}{*}{ FFD } & Identity contrast & $5.30(200 \mathrm{~ms})$ & $-0.02(-4 \mathrm{~ms})$ & $-0.05(-10 \mathrm{~ms})$ & $0.01(2 \mathrm{~ms})$ & 0.928 \\
\hline & Vowel contrast & $5.30(200 \mathrm{~ms})$ & $-0.01(-2 \mathrm{~ms})$ & $-0.04(-8 \mathrm{~ms})$ & $0.02(4 \mathrm{~ms})$ & 0.814 \\
\hline \multirow[t]{2}{*}{ GD } & Identity contrast & $5.38(217 \mathrm{~ms})$ & $-0.01(-2 \mathrm{~ms})$ & $-0.05(-11 \mathrm{~ms})$ & $0.03(7 \mathrm{~ms})$ & 0.673 \\
\hline & Vowel contrast & $5.38(217 \mathrm{~ms})$ & $-0.01(-2 \mathrm{~ms})$ & $-0.05(-11 \mathrm{~ms})$ & $0.03(7 \mathrm{~ms})$ & 0.713 \\
\hline \multirow[t]{2}{*}{ GP } & Identity contrast & $5.49(242 \mathrm{~ms})$ & $-0.04(-9 \mathrm{~ms})$ & $-0.09(-21 \mathrm{~ms})$ & $-0.00(-0 \mathrm{~ms})$ & 0.976 \\
\hline & Vowel contrast & $5.49(242 \mathrm{~ms})$ & $-0.01(-2 \mathrm{~ms})$ & $-0.06(-14 \mathrm{~ms})$ & $0.04(10 \mathrm{~ms})$ & 0.652 \\
\hline \multirow[t]{2}{*}{ Reg. out } & Identity contrast & $-2.40(8.3 \%)$ & $-0.39(-2.5 \%)$ & $-0.93(-4.8 \%)$ & $0.08(0.63 \%)$ & 0.946 \\
\hline & Vowel contrast & $-2.40(8.3 \%)$ & $-0.06(-0.4 \%)$ & $-0.48(-3.0 \%)$ & $0.35(3 \%)$ & 0.621 \\
\hline
\end{tabular}

\section{A.2. Preview effects on word $n+1$}

It is also possible that, in cases where readers' eyes landed on word $n+1$ (i.e. the article an) prior to word $n+2$, preview effects may have appeared on word $n+1$. Prior to discussing fixation times on word $n+1$ it is worth noting that the eyes only landed on this word in a third of trials. As such, in both of our experiments there was very little data for this analysis, and so estimates of any effects were highly prone to noise. As such, finding any strong evidence in favour of an effect of our manipulation was highly unlikely, even if such an effect was present. None the less, we do present such an analysis below. The Bayesian linear mixed models for this analysis were structured in an identical manner as the models which 
examined reading behaviour on word $n+2$. Mean reading times on this word for Experiment 1 and Experiment 2 can be seen in Table A.5 and Table A.7, while the output of the Bayesian linear mixed models can be seen in Table A.6 and Table A.8.

Table A.5

Mean (standard error) reading times on the word an in experiment 1.

\begin{tabular}{lll}
\hline & Identity/vowel & Violation/consonant \\
\hline First fixation duration & $212(4.46)$ & $211(4.44)$ \\
Gaze duration & $219(4.99)$ & $215(4.89)$ \\
Go-past time & $264(8.52)$ & $269(9.87)$ \\
Regressions out & $0.14(0.02)$ & $0.17(0.02)$ \\
\hline
\end{tabular}

Table A.6

Output from our Bayesian mixed effects models for Reading Times on an in Experiment 1. Mean effects estimates (b), 95\% confidence intervals, and the probability of our effect being in the expected direction are reported. Log-units output by the model are reported, followed by values translated into fixation times and probabilities in parentheses.

\begin{tabular}{|c|c|c|c|c|c|}
\hline & Intercept & $B$ & L95\% & U95\% & $\mathrm{P}(b>0)$ \\
\hline FFD & $5.30(200)$ & $-0.00(-0)$ & $-0.06(-12)$ & $0.05(10)$ & 0.460 \\
\hline GD & $5.32(204)$ & $-0.01(-2)$ & $-0.07(-14)$ & $0.04(8)$ & 0.321 \\
\hline GP & 5.47 (237) & $0.01(2)$ & $-0.08(-18)$ & $0.09(22)$ & 0.557 \\
\hline Regs. out & $-2.30(0.09)$ & $0.39(0.04)$ & $-0.42(-0.03)$ & $1.20(0.16)$ & 0.829 \\
\hline
\end{tabular}

In Experiment 1 fixation times on an were highly similar in both conditions, with any numerical differences varying in direction from measure to measure. A similar lack of systematic effects was present in Experiment 2, whereby numerical differences were generally small, and varied in direction across measures. Thus, it seems unlikely that effects of our manipulation emerged in fixation times on word $n+1$, although once again it seems unlikely that we would have had adequate power to detect such effects if they were present.

Table A.7

Mean (standard error) reading times on the word an in Experiment 2.

\begin{tabular}{llll}
\hline & Identity & Vowel & Consonant \\
\hline FFD & $208(3.63)$ & $213(3.91)$ & $205(4.07)$ \\
GD & $213(4.14)$ & $221(4.44)$ & $214(4.75)$ \\
Go-past & $251(6.77)$ & $260(7.63)$ & $266(8.48)$ \\
Regression out & $0.15(0.02)$ & $0.15(0.02)$ & $0.18(0.02)$ \\
\hline
\end{tabular}

Table A.8

Output from our Bayesian mixed effects models for Reading Times on an in Experiment 2. Mean effects estimates (b), $95 \%$ confidence intervals, and the probability of our effect being in the expected direction are reported. Log-units output by the model are reported, followed by values translated into fixation times and probabilities in parentheses.

\begin{tabular}{|c|c|c|c|c|c|c|}
\hline & & Intercept & $B$ & $\mathrm{~L} 95 \%$ & U95\% & $\mathrm{P}(b>/<0)$ \\
\hline \multirow[t]{2}{*}{ FFD } & Identity contrast & $5.31(202 \mathrm{~ms})$ & $-0.01(-2 \mathrm{~ms})$ & $-0.05(-10 \mathrm{~ms})$ & $0.04(8 \mathrm{~ms})$ & 0.636 \\
\hline & Violation contrast & $5.31(202 \mathrm{~ms})$ & $-0.03(-6 \mathrm{~ms})$ & $-0.08(-16 \mathrm{~ms})$ & $0.02(4 \mathrm{~ms})$ & 0.113 \\
\hline \multirow[t]{2}{*}{ GD } & Identity contrast & $5.33(206 \mathrm{~ms})$ & $-0.02(-4 \mathrm{~ms})$ & $-0.07(-14 \mathrm{~ms})$ & $0.03(6 \mathrm{~ms})$ & 0.782 \\
\hline & Violation contrast & $5.33(206 \mathrm{~ms})$ & $-0.03(-6 \mathrm{~ms})$ & $-0.08(16 \mathrm{~ms})$ & $0.03(6 \mathrm{~ms})$ & 0.168 \\
\hline \multirow[t]{2}{*}{ GP } & Identity contrast & $5.44(230 \mathrm{~ms})$ & $-0.00(-0 \mathrm{~ms})$ & $-0.07(-16 \mathrm{~ms})$ & $0.06(14 \mathrm{~ms})$ & 0.515 \\
\hline & Violation contrast & $5.44(230 \mathrm{~ms})$ & $0.03(7 \mathrm{~ms})$ & $-0.05(-11 \mathrm{~ms})$ & $0.10(24 \mathrm{~ms})$ & 0.755 \\
\hline \multirow[t]{2}{*}{ Reg. out } & Identity contrast & $-2.07(8.9 \%)$ & $0.01(0.1 \%)$ & $-0.56(-4.5 \%)$ & $0.57(7 \%)$ & 0.484 \\
\hline & Violation contrast & $-2.07(8.9 \%)$ & $0.13(1.4 \%)$ & $-0.54(-4.4 \%)$ & $0.73(9.5 \%)$ & 0.685 \\
\hline
\end{tabular}

\section{References}

Andrews, S., \& Veldre, A. (2019). What is the most plausible account of the role of parafoveal processing in reading? Language and Linguistics Compass, 13. https://doi.org/ $10.1111 /$ Inc3.12344.

Angele, B., Laishley, A. E., Rayner, K., \& Liversedge, S. P. (2014). The effect of high- and low-frequency previews and sentential fit on word skipping during reading. Journal of Experimental Psychology: Learning, Memory, and Cognition, 40, 1181-1203. https:// doi.org/10.1037/a0036396.

Angele, B., \& Rayner, K. (2011). Parafoveal processing of word $n+2$ during reading: Do the preceding words matter? Journal of Experimental Psychology: Human Perception and Performance, 37, 1210-1220. https://doi.org/10.1037/a0023096.

Angele, B., \& Rayner, K. (2013). Processing in the parafovea: Are articles skipped automatically? Journal of Experimental Psychology: Learning, Memory, and Cognition, 39, 649-663. https://doi.org/10.1037/a0029294.

Angele, B., Slattery, T. J., \& Rayner, K. (2016). Two stages of parafoveal processing during reading: Evidence from a display change detection task. Psychonomic Bulletin \& Review, 23, 1241-1249. https://doi.org/10.3758/s13423-015-0995-0.

Angele, B., Slattery, T. J., Yang, J., Kliegl, R., \& Rayner, K. (2008). Parafoveal processing in reading: Manipulating $\mathrm{n}+1$ and $\mathrm{n}+2$ previews simultaneously. Visual Cognition, 16, 697-707. https://doi.org/10.1080/13506280802009704.

Ashby, J., \& Rayner, K. (2004). Representing syllable information during silent reading: Evidence from eye movements. Language and Cognitive Processes, 19, 391-426.

Ashby, J., Treiman, R., Kessler, B., \& Rayner, K. (2006). Vowel processing during silent reading: Evidence from eye movements. Journal of Experimental Psychology: Learning, Memory, and Cognition, 32, 416-424.

Briihl, D., \& Inhoff, A. W. (1995). Integrating information across fixations during reading: 
The use of orthographic bodies and exterior letters. Journal of Experimental Psychology: Learning Memory and Cognition, 21, 55-67.

Brothers, T., \& Traxler, M. J. (2016). Anticipating syntax during reading: Evidence from the boundary change paradigm. Journal of Experimental Psychology: Learning Memory and Cognition, 42, 1894-1906. https://doi.org/10.1037/xlm0000257.

Chace, K. H., Rayner, K., \& Well, A. D. (2005). Eye movements and phonological preview: Effects of reading skill. Canadian Journal of Experimental Psychology, 59, 209-217.

Cutter, M. G., Drieghe, D., \& Liversedge, S. P. (2014). Preview benefit in English spaced compounds. Journal of Experimental Psychology: Learning Memory and Cognition, 40, 1778-1786. https://doi.org/10.1037/xlm0000013.

Cutter, M. G., Drieghe, D., \& Liversedge, S. P. (2015). How is information integrated across fixations in reading? In A. Pollatsek, \& R. Treiman (Eds.). The Oxford handbook of reading (pp. 245-260). New York, NY: Oxford University Press.

Cutter, M. G., Drieghe, D., \& Liversedge, S. P. (2017). Is orthographic information from multiple parafoveal words processed in parallel: An eye-tracking study. Journal of Experimental Psychology: Human Perception and Performance, 43, 1550-1567. https:// doi.org/10.1037/xhp0000408.

Cutter, M. G., Martin, A. E., \& Sturt, P. (2020a). The activation of contextually predictable words in syntactically illegal positions. Quarterly Journal of Experimental Psychology. Advance online publication. https://doi.org/10.1177/1747021820911021.

Cutter, M. G., Martin, A. E., \& Sturt, P. (2020b). Capitalization interacts with syntactic complexity. Journal of Experimental Psychology: Learning, Memory, and Cognition, 46 1146-1164. https://doi.org/10.1037/xlm0000780.

DeLong, K. A., Urbach, T. P., \& Kutas, M. (2005). Probabilistic word pre-activation during language comprehension inferred from electrical brain activity. Nature Neuroscience, 8, 1117-1121. https://doi.org/10.1038/nn1504.

Drieghe, D., Pollatsek, A., Staub, A., \& Rayner, K. (2008). The word grouping hypothesis and eye movements during reading. Journal of Experimental Psychology: Learning, Memory, and Cognition, 34(6), 1552-1560. https://doi.org/10.1037/a0013017.

Hohenstein, S., \& Kliegl, R. (2014). Semantic preview benefit during reading. Journal of Experimental Psychology: Learning, Memory, and Cognition, 40, 166-190.

Hyönä, J., Bertram, R., \& Pollatsek, A. (2004). Are long compound words identified serially via their constituents? Evidence from an eyemovement-contingent display change study. Memory \& Cognition, 32, 523-532.

Ito, A., Martin, A. E., \& Nieuwland, M. S. (2016). How robust are prediction effects in language comprehension? Failure to replicate article-elicited N400 effects. Language, Cognition, and Neuroscience, 32, 954-965. https://doi.org/10.1080/23273798.2016. 1242761.

Johnson, R. L., Perea, M., \& Rayner, K. (2007). Transposed-letter effects in reading: Evidence from eye movements and parafoveal preview. Journal of Experimental Psychology: Human Perception and Performance, 33, 209-229.

Kliegl, R., Risse, S., \& Laubrock, J. (2007). Preview benefit and parafoveal-on-foveal effects from word $n+2$. Journal of Experimental Psychology: Human Perception and Performance, 33, 1250-1255. https://doi.org/10.1037/0096-1523.33.5.1250.

Martin, A. E. (2016). Language processing as cue integration: Grounding the psychology of language in perception and neurophysiology. Frontiers in Psychology, 7, 120.

McConkie, G. W., \& Rayner, K. (1975). The span of effective stimulus during a fixation in reading. Perception \& Psychophysics, 17, 578-586.

Miellet, S., \& Sparrow, L. (2004). Phonological codes are assembled before word fixation: Evidence from boundary paradigm in sentence reading. Brain and Language, 90 , 299-310. https://doi.org/10.1016/S0093-934X(03)00442-5.

Pollatsek, A., Lesch, M., Morris, R. K., \& Rayner, K. (1992). Phonological codes are used in integrating information across saccades in word identification and reading. Journal of Experimental Psychology: Human Perception and Performance, 18, 148-162.

Radach, R. (1996). (1996) Blickbewegungen beim Lesen: Psychologische Aspekte der Determination von Fixationspositionen (Eye Movements in Reading). Münster/New York: Waxmann.

Radach, R., Inhoff, A. W., Glover, L., \& Vorstius, C. (2013). Contextual constraint and N +2 preview effects in reading. The Quarterly Journal of Experimental Psychology, 66, 619-633. https://doi.org/10.1080/17470218.2012.761256.

Rayner, K. (1975). The perceptual span and peripheral cues in reading. Cognitive Psychology, 7, 65-81.

Rayner, K., Juhasz, B. J., \& Brown, S. J. (2007). Do readers obtain preview benefit from word $\mathrm{N}+2$ ? A test of serial attention shift versus distributed lexical processing models of eye movement control in reading. Journal of Experimental Psychology: Human Perception and Performance, 33, 230-245. https://doi.org/10.1037/00961523.33.1.230

Rayner, K., \& Schotter, E. R. (2014). Semantic preview benefit in reading English: The effect of initial letter capitalization. Journal of Experimental Psychology: Human
Perception and Performance, 40, 1617-1628. https://doi.org/10.1037/a0036763.

Reichle, E. D., Pollatsek, A., \& Rayner, K. (2006). E-Z reader: A cognitive-control, serialattention model of eye-movement behavior during reading. Cognitive Systems Research, 7, 4-22. https://doi.org/10.1016/j.cogsys.2005.07.002.

Reichle, E. D., Warren, T., \& McConnell, K. (2009). Using EZ reader to model the effects of higher level language processing on eye movements during reading. Psychonomic Bulletin \& Review, 16, 1-21. https://doi.org/10.3758/PBR.16.1.1.

Risse, S., \& Kliegl, R. (2012). Evidence for delayed parafoveal-on-foveal effects from word $\mathrm{n}+2$ in reading. Journal of Experimental Psychology: Human Perception and Performance, 38, 1026-1042. https://doi.org/10.1037/a0027735.

Schotter, E. R. (2013). Synonyms provide semantic preview benefit in English. Journal of Memory and Language, 69, 619-633.

Schotter, E. R. (2018). Reading ahead by hedging out bets on seeing the future: Eye tacking and electrophysiology evidence for parafoveal lexical processing and saccadic control by partial word recognition. Psychology of Learning and Motivation, 68, 263-298. https://doi.org/10.1016/bs.plm.2018.08.011.

Schotter, E. R., \& Jia, A. (2016). Semantic and plausibility preview benefit effects in English: Evidence from eye movements. Journal of Experimental Psychology: Learning, Memory, and Cognition, 42, 1839-1866. https://doi.org/10.1037/xlm0000281.

Schotter, E. R., \& Leinenger, M. (2016). Reversed preview benefit effects: Forced fixations emphasize the importance of parafoveal vision for efficient reading. Journal of Experimental Psychology: Human Perception and Performance, 42(12), 2039-2067. https://doi.org/10.1037/xhp0000270.

Schotter, E. R., Leinenger, M., \& von der Malsburg, T. (2018). When your mind skips what your eyes fixate: How forced fixations lead to comprehension illusions in reading. Psychonomic Bulletin \& Review, 25, 1884-1890. https://doi.org/10.3758/s1342.

Schotter, E. R., Reichle, E. D., \& Rayner, K. (2014). Rethinking parafoveal processing in reading: Serial-attention models can explain semantic preview benefit and $\mathrm{N}+2$ preview effects. Visual Cognition, 22, 309-333. https://doi.org/10.1080/13506285. 2013.873508.

Schotter, E. R., von der Malsburg, T., \& Leinenger, M. (2019). Forced fixations, transsaccadic integration, and word recognition: Evidence for a hybrid mechanism of saccade triggering in reading. Journal of Experimental Psychology: Learning, Memory, and Cognition, 45, 677-688. https://doi.org/10.1037/xlm0000617.

Slattery, T. J., Pollatsek, A., \& Rayner, K. (2006). The time course of phonological and orthographic processing of acronyms in reading: Evidence from eye movements. Psychonomic Bulletin \& Review, 13, 412-417. https://doi.org/10.3758/BF03193862.

Staub, A. (2011). Word recognition and syntactic attachment in reading: Evidence for a staged architecture. Journal of Experimental Psychology: General, 140(3), 407-433. https://doi.org/10.1037/a0023517.

Vasilev, M. R., \& Angele, B. (2017). Parafoveal preview effects from word $n+1$ and word $n+2$ during reading: A critical review and Bayesian meta-analysis. Psychonomic Bulletin \& Review, 24, 666-689. https://doi.org/10.3758/s13423-016-1147-x.

Vasilev, M. R., Yates, M., \& Slattery, T. J. (2019). Do readers integrate phonological codes across saccades? A Bayesian meta-analysis and a survey of the unpublished literature. Journal of Cognition, 2, 1-29. https://doi.org/10.5334/joc. 87.

Veldre, A., \& Andrews, S. (2016). Parafoveal preview effects depend on both preview plausibility and target predictability. The Quarterly Journal of Experimental Psychology, $1-12$.

Veldre, A., \& Andrews, S. (2018a). Beyond cloze probability: Parafoveal processing of semantic and syntactic information during reading. Journal of Memory and Language, 100, 1-17. https://doi.org/10.1016/j.jml.2017.12.002.

Veldre, A., \& Andrews, S. (2018b). How does foveal processing difficulty affect parafoveal processing during reading? Journal of Memory and Language, 103, 74-90. https://doi. org/10.1016/j.jml.2018.08.001.

Veldre, A., Reichle, E. D., Wong, R., \& Andrews, S. (2020). The effect of contextual plausibility on word skipping during reading. Cognition, 197. https://doi.org/10. 1016/j.cognition.2020.104184.

Wakeford, L., \& Murray, W. (2013). Effects of parafoveal plausibility during reading. Proceedings of the Annual Meeting of the Cognitive Science Society, 35. https:// escholarship.org/uc/item/9k45772m.

White, S., \& Liversedge, S. P. (2004). Orthographic familiarity influences initial eye fixation positions in reading. European Journal of Cognitive Psychology, 16, 52-78. https://doi.org/10.1080/09541440340000204.

Yang, J., Li, N., Wang, S., Slattery, T. J., \& Rayner, K. (2014). Encoding the target or the plausible preview word? The nature of the plausibility preview benefit in reading Chinese. Visual Cognition, 22, 193-213. https://doi.org/10.1080/13506285.2014. 890689 . 